\title{
Phytanic acid: measurement of plasma concentrations by gas-liquid chromatography-mass spectrometry analysis and associations with diet and other plasma fatty acids
}

\author{
Naomi E. Allen ${ }^{1}$, Philip B. Grace ${ }^{2}$, Annette Ginn ${ }^{2}$, Ruth C. Travis ${ }^{1}$, Andrew W. Roddam ${ }^{1}$, \\ Paul N. Appleby ${ }^{1}$ and Timothy Key ${ }^{1}$ \\ ${ }^{1}$ Cancer Epidemiology Unit, University of Oxford, Richard Doll Building, Roosevelt Drive, Oxford OX3 7LF, UK \\ ${ }^{2}$ HFL Limited, Newmarket Road, Fordham, Cambs CB7 5WW, UK
}

(Received 7 March 2007 - Revised 5 July 2007 - Accepted 20 July 2007)

Epidemiological data suggest that a diet rich in animal foods may be associated with an increased risk of several cancers, including cancers of the prostate, colorectum and breast, but the possible mechanism is unclear. It is hypothesised that phytanic acid, a C20 branched-chain fatty acid found predominantly in foods from ruminant animals, may be involved in early cancer development because it has been shown to up regulate activity of $\alpha$-methylacyl-coenzyme A racemase, an enzyme commonly found to be over-expressed in tumour cells compared with normal tissue. However, little is known about the distribution of plasma phytanic acid concentrations or its dietary determinants in the general population. The primary aim of the present cross-sectional study was to determine circulating phytanic acid concentrations among ninety-six meat-eating, lacto-ovo-vegetarian and vegan women, aged 20-69 years, recruited into the Oxford component of the European Prospective Investigation into Cancer and Nutrition (EPIC-Oxford). Meat-eaters had, on average, a 6.7-fold higher geometric mean plasma phytanic acid concentration than the vegans (5.77 $v$. $0.86 \mu \mathrm{mol} / 1 ; P<0.0001)$ and a $47 \%$ higher mean concentration than the vegetarians $(5.77 v .3 .93 \mu \mathrm{mol} / 1 ; P=0.016)$. The strongest determinant of plasma phytanic acid concentration appeared to be dairy fat intake $(r 0.68 ; P<0.0001)$; phytanic acid levels were not associated with age or other lifestyle factors. These data show that a diet high in fat from dairy products is associated with increased plasma phytanic acid concentration, which may play a role in cancer development.

Phytanic acid: Measurement: Diet: Dairy fat: EPIC-Oxford

The possible role of diet in the aetiology of cancer was highlighted in the $1970 \mathrm{~s}$ when it was noted that Western countries that have diets high in animal products have high rates of cancers of the breast, colorectum and prostate ${ }^{1}$. The mechanism through which a high consumption of animal foods may increase the risk of these cancers is not known, although an increase in insulin-like growth factor$\mathrm{I}^{2,3}$ has been suggested. A recent hypothesis is that a diet high in animal products may be associated with an increased risk of prostate cancer due to its phytanic acid content ${ }^{4}$, and such a mechanism might also conceivably affect cancers of the breast and colorectum.

Interest in phytanic acid (3,7,11,15-tetramethylhexadecanoic acid), a C20 branched-chain fatty acid found predominantly in red meat and dairy products, originated from the finding of extremely high plasma and tissue concentrations in individuals with certain genetic metabolic disorders, such as Refsum disease ${ }^{5}$. It has been proposed that moderately elevated concentrations of phytanic acid, within the normal range, may be associated with cancer development.
Phytanic acid has been shown to up regulate activity of $\alpha$ methylacyl-coenzyme A racemase (AMACR) ${ }^{5,6}$, an enzyme required for the peroxisomal $\beta$-oxidation of phytanic acid, and which has been shown to be over-expressed in cancers of the prostate, breast and colon and their early precursor lesions, compared with normal tissue $\mathrm{e}^{7-14}$. This has led to the hypothesis that AMACR over-expression may be a common mechanism through which a high intake of phytanic acid from animal foods increases the early stage of cancer development.

Phytanic acid is derived from phytol, a breakdown product of chlorophyll. Phytol is not produced in the human gut, but micro-organisms present in the gastrointestinal system of ruminants can break down chlorophyll to release phytol, which is then converted into phytanic acid ${ }^{15}$. The sources of phytanic acid in the UK diet are therefore thought to be derived almost exclusively from ruminant animals (beef, lamb and products containing the milk fats of cows, sheep and goats), although some fatty fish whose food chain includes large amounts of plankton also contain phytanic

Abbreviations: AMACR, $\alpha$-methylacyl-coenzyme A racemase; EPIC-Oxford, Oxford component of the European Prospective Investigation into Cancer and Nutrition; QC, quality control.

* Corresponding author: Professor Timothy Key, fax +44 1865 289610, email tim.key@ceu.ox.ac.uk 
$\operatorname{acid}^{16}$. In man, phytanic acid is thought to be a minor component of total fatty acids $(<0.3 \%)^{16}$ and has not been investigated in large-scale studies. Further, little is known about the distribution of phytanic acid concentrations in the general population, or which foods contribute most to circulating levels.

Here, we report on the association between dietary intake and plasma phytanic acid concentration in ninety-six British women meat-eaters, lacto-ovo-vegetarians and vegans recruited into the Oxford component of the European Prospective Investigation into Cancer and Nutrition (EPIC-Oxford). A secondary aim is to examine the associations between phytanic acid and dietary intake of dairy and ruminant foods and to compare these associations with those for plasma phospholipid levels of pentadecanoic (15: 0) and heptadecanoic acid (17: 0), two other fatty acids which are also synthesised in the rumen of cows and sheep and which are already used as biomarkers of dairy and ruminant food intake. We also describe the details of the assay developed by us to be suitable for measuring plasma phytanic acid concentrations in the context of large-scale epidemiological studies.

\section{Methods}

\section{Study design}

Between 1993 and 1999, 58000 individuals aged 20 years and above and living in the UK were recruited into EPICOxford $^{17,18}$. Participants were recruited through collaborating general practitioners, vegetarian and vegan societies, health food magazines, and from friends and relatives of the participants. All participants completed a questionnaire that included details of age, anthropometric, smoking and other lifestyle factors as well as a detailed semi-quantitative FFQ. Participants gave written informed consent to the study, and the study protocol was approved by the Multi-Centre Research Ethics Committee for Scotland.

A $30 \mathrm{ml}$ non-fasting blood sample was obtained from approximately $30 \%$ of volunteers, on average 4 months after completion of the questionnaire. Whole blood was sent through the mail to the laboratory at ambient temperature, where it was processed and stored in twelve $0.5 \mathrm{ml}$ straws of serum, plasma, erythrocytes and buffy coat fractions at $-196^{\circ} \mathrm{C}$. Where available, any remaining plasma was stored at $-80^{\circ} \mathrm{C}$ in $2 \mathrm{ml}$ vials and these plasma samples were used for the present study. All dates of blood sample and questionnaire processing, time of day at blood collection, time since last meal at blood collection and medication taken on day of blood collection were recorded.

The present study includes ninety-six women comprising approximately equal numbers of women in each of five 10 -year age groups, from age 20 to 69 years. In order to maximise the variation in dietary intake, we selected forty-six vegan women (defined as those who reported not eating any animal products), twenty-five lacto-ovo-vegetarians (defined as those who reported not eating meat or fish but did consume dairy products and/or eggs) and twenty-five meat-eaters. Subjects were not eligible if they had a self-reported history of cancer or diabetes, or were pregnant or taking oral contraception or hormone replacement therapy at the time of recruitment.

\section{Dietary assessment}

In the FFQ, subjects were asked to state how frequently they ate each of a range of foods over the past 1 year, based on nine frequency categories, ranging from never or less than once per month to six or more times per $\mathrm{d}$. These questions covered 130 foods and beverages, and also allowed subjects to add food products that were not specified on the questionnaire. The foods considered for this analysis included total meat products (beef and beefburgers, lamb, poultry, pork, bacon, ham, Spam, sausages, meat pie and liver), fish and fish products (white fish, oily fish, fried fish, fish cakes, shellfish and fish roe products) and dairy products (milk, cheese, cottage cheese, yoghurt, dairy desserts, cream and quiche). Estimated daily nutrient intakes were calculated by multiplying the nutrient content of each food of a specific portion size by the frequency of consumption as stated on the $\mathrm{FFQ}^{18,19}$. Average portion sizes were based on those designated by the Ministry of Agriculture, Fisheries and Food ${ }^{20}$.

\section{Statistical analysis}

Plasma concentrations of phytanic acid and other fatty acids were logarithmically transformed to approximate normal distributions. The associations between diet group and baseline characteristics were analysed using one-way ANOVA for continuous variables and the $\chi^{2}$ test of association for categorical variables. The associations between plasma phytanic acid concentration and lifestyle factors (age: $20-29,30-39,40-49$, 50-59, 60-69 years; BMI in quartiles: $<20 \cdot 1,20 \cdot 1-21 \cdot 7$, $21 \cdot 8-24 \cdot 1,24 \cdot 2+\mathrm{kg} / \mathrm{m}^{2}$; smoking: never, former, current), diet group (meat-eaters, lacto-ovo-vegetarian, vegan) and variables relating to the collection and processing of the blood samples, which included time of day at blood collection (00.00-09.29, 09.30-10.44, 10.45-13.29, 13.30-23.59 hours), time since last meal at blood collection $(<1 \cdot 15$, $1 \cdot 15-1 \cdot 59,2 \cdot 00-3 \cdot 29,3 \cdot 30+\mathrm{h}$ ), days between blood collection and blood processing $(1,2,3,4+\mathrm{d})$ and assay batch $(1,2,3,4)$ was also examined using ANOVA and the fitted mean concentrations and their corresponding $95 \% \mathrm{CI}$ are presented as back-transformed values. All $P$ values refer to tests of heterogeneity between the group means, using the $F$ statistic from the ANOVA table, unless otherwise stated; $t$ tests were used to compare the mean phytanic acid concentration between pairs of diet groups.

The associations between phytanic acid, pentadecanoic and heptadecanoic acid and animal foods and nutrient intakes were examined using the Spearman rank correlation among meateaters and vegetarians, where appropriate. A $P$ value of less than 0.05 was considered statistically significant and all significance tests were two-sided. Analyses were performed using Stata version 9 (StataCorp LP, College Station, TX, USA).

\section{Laboratory assay}

Plasma samples $(2 \mathrm{ml})$ for all study participants were shipped on dry ice to HFL Ltd (Fordham, Cambs, UK) for analysis. Extraction and quantification of total phytanic acid in plasma (i.e. the sum of phytanic acid in free and conjugated 
forms) was performed using GLC-MS and all measurements were carried out blinded to the subject's dietary group.

\section{Determination of plasma phytanic acid}

Plasma $(50 \mu \mathrm{l})$ was allowed to thaw to room temperature before adding [3-methyl- ${ }^{2} \mathrm{H}_{3}$ ]phytanic acid (Dr H. J. ten Brink, VU Medical Center, Amsterdam, the Netherlands) in toluene $(50 \mu \mathrm{l} ; 1.3 \mu \mathrm{g} / \mathrm{ml})$. In order to determine the optimal method for releasing free phytanic acid in the greatest concentration, samples from pooled plasma samples were subjected to acidic hydrolysis or saponification using four different procedures: (i) ethanolic potassium hydroxide $(5 \%(\mathrm{w} / \mathrm{v}), 1 \mathrm{ml})$ for $1 \mathrm{~h}$ at $60^{\circ} \mathrm{C}^{21}$; (ii) hydrochloric acid in acetonitrile $(0.5 \mathrm{M}$, $2 \mathrm{ml}$ ) for $45 \mathrm{~min}$ at $110^{\circ} \mathrm{C}$; (iii) sodium hydroxide in methanol $(1 \mathrm{M}, 2 \mathrm{ml})$ for $45 \mathrm{~min}$ at $110^{\circ} \mathrm{C}$; (iv) a combination of (ii) and $\left(\right.$ iii) ${ }^{22}$. The mean concentration of phytanic acid found in samples from a single plasma sample were: 3.35 (SD 0.016), 1.85 (SD 0.067), 3.26 (SD 0.048) and 3.12 (SD 0.064) $\mu \mathrm{mol} / \mathrm{l}$, for each of the four methods, respectively. As ethanolic potassium hydroxide yielded the highest concentrations of free phytanic acid, this procedure was used for all samples in this analysis. Water $(1 \mathrm{ml})$ and hexane $(4 \mathrm{ml})$ were added and the samples shaken for $20 \mathrm{~min}$ before discarding the organic layer. Glacial acetic acid $(100 \mu \mathrm{l})$ and hexane $(4 \mathrm{ml})$ were added and the samples shaken for a further $20 \mathrm{~min}$ before the hexane layer was removed and dried in a centrifugal vacuum evaporator. The dried samples were derivatised to the tert-butyldimethylsilyl ethers by adding pyridine $(50 \mu \mathrm{l})$ and $N$-tert-butyldimethylsilyl- $N$-methyltrifluoroacetamide $(50 \mu \mathrm{l})$ and heating at $80^{\circ} \mathrm{C}$ for $30 \mathrm{~min}$.

\section{Gas-liquid chromatography-mass spectrometry analysis}

A Trace 2000 Series gas chromatograph (ThermoQuest, Waltham, MA, USA) interfaced to a Voyager mass spectrometer (ThermoQuest) was used for GLC-MS analyses. Data acquisition and processing were carried out using Xcalibur 1.1 and LCQuan 1.1 software (ThermoQuest). A BPX5 column (25 m $\times 0.25 \mathrm{~mm}, 0.22 \mu \mathrm{m}$ film thickness; SGE, Ringwood, Victoria, Australia) was used for all analyses. Operating conditions were as follows: injector port temperature $300^{\circ} \mathrm{C}$; injection volume $1 \mu \mathrm{l}$ in splitless mode; carrier gas $\mathrm{He}$ at a constant flow of $1.1 \mathrm{ml} / \mathrm{min}$; oven temperature program $100^{\circ} \mathrm{C}$ held for $0.5 \mathrm{~min}$ then increased at $30^{\circ} \mathrm{C} / \mathrm{min}$ to $210^{\circ} \mathrm{C}$ and held for $1 \mathrm{~min}$, then at $10^{\circ} \mathrm{C} / \mathrm{min}$ to $300^{\circ} \mathrm{C}$ and held for $1 \mathrm{~min}$; source temperature $220^{\circ} \mathrm{C}$; ionisation by electron ionisation (70 eV); emission current $150 \mu \mathrm{A}$. Analysis was performed in the selected ion monitoring mode. Ions arising from the loss of the tert-butyl group, [M-57 $]^{+}$, were monitored for phytanic acid and the internal standard $\left[3-\right.$ methyl- $\left.{ }^{2} \mathrm{H}_{3}\right]$ phytanic acid, at $\mathrm{m} / \mathrm{z} 369$ and 372, respectively.

Other studies using GLC-MS analysis of the tert-butyldimethylsilyl ethers of fatty acids have added bromine to prevent co-elution of phytanic acid with linoleic acid, as brominated linoleic acid elutes at a later retention time ${ }^{22}$. In the present study, GC conditions were optimised such that baseline chromatographic resolution was achieved between linoleic acid and phytanic acid, with retention times of 11.9 and $11.5 \mathrm{~min}$ respectively, with no need for the addition of bromine.
The detection limit of $0.032 \mu \mathrm{mol} / 1$ was sufficient to enable quantification of all samples tested. Calibration standards were prepared by spiking known concentrations of phytanic acid into $50 \mu \mathrm{l}$ samples of PBS. Six calibration levels were used $(0,0.032,0.16,0.32,3.2$ and $9.6 \mu \mathrm{mol} / \mathrm{l})$, with two injections being made at each concentration. Calibration standards were injected both before and after analyses of the samples and the final calibration curves were constructed from both series of injections. A linear regression line was used, weighted $1 / x$, and coefficients of determination $\left(R^{2}\right)$ were $>0.999$ for all batches.

\section{Quality control and stability}

Three drug-free plasma samples, well characterised for their phytanic acid concentration, were used for quality control (QC) purposes (Richmond Pharmacology Ltd, Tooting, London, UK). The CV were based on the analysis of QC samples across six batches, with at least two replicates in each batch. The mean intra- and inter-assay CV were 1.8 and $3.2 \%$, respectively.

In order to assess the stability of phytanic acid when left at room temperature, concentrations were compared in five replicates of each of two QC samples; one which had been left at room temperature for $4 \mathrm{~h}$ before extraction, and one which was extracted immediately after thawing in the normal way. The phytanic acid concentration for the samples left for $4 \mathrm{~h}$ varied from those that were extracted immediately by an average of 5.0 and $5.8 \%$, for each of the two sets of samples. This is much less than the $15 \%$ variation generally considered acceptable for $4 \mathrm{~h}$ stability and suggests that phytanic acid concentrations are stable at room temperature over the timescale used for the extraction process.

To evaluate the stability of phytanic acid concentrations in samples that may have undergone several freeze-thaw cycles, five replicates of each of two QC samples were subjected to zero, one, two, or three freeze-thaw cycles (at $-80^{\circ} \mathrm{C}$ ), with at least $24 \mathrm{~h}$ between each thawing period. The range of deviations of phytanic acid concentration in the samples subjected to freeze-thaw cycles from those not subjected to freeze-thaw cycles was 0.4 to $3.3 \%$ across both samples, suggesting that repeated freezing and thawing of samples does not substantially affect phytanic acid concentrations. However, all samples in the present analysis had undergone no previous freeze-thaw cycle before the phytanic acid assay.

Samples with phytanic acid concentrations above the upper detection threshold of $9.6 \mu \mathrm{mol} / 1$ ( $4 \%$ of all samples) were diluted 1:1 with PBS ( $25 \mu \mathrm{l}$ of each) before re-extraction and analysis. When tested with three well-characterised QC samples, this procedure was found to produce deviations from the target values of $0.2,0.8$ and $3.6 \%$, and was therefore deemed appropriate.

\section{Determination of plasma pentadecanoic acid and heptadecanoic acid}

After addition of butylated hydroxy toluene $(100 \mu \mathrm{l} ; 1 \mathrm{mg} / \mathrm{ml}$ in methanol) and di-palmitoyl-D31-phosphatidylcholine $(40 \mu \mathrm{l}$; $0.5 \mathrm{mg} / \mathrm{ml}$ in chloroform) to plasma $(200 \mu \mathrm{l})$, lipids were extracted using chloroform-methanol $(2: 1 ; 4 \mathrm{ml})$ plus methanol $(0.5 \mathrm{ml})$. The upper layer was removed and mixed with aqueous 
sodium chloride solution $(0.83 \% ; 1 \mathrm{ml})$. After mixing, the lower phase was evaporated to dryness in a centrifugal vacuum evaporator. Dried extracts were redissolved in chloroform-methanol $(2: 1 ; 200 \mu \mathrm{l})$, before isolation of phospholipids on an LC-Si silica SPE cartridge $(500 \mathrm{mg} / 6 \mathrm{ml}$; Supelco, Poole, Dorset, UK). After elution of the phospholipids in methanol, the extracts were dried and transmethylated using MethPrep II $(25 \mu \mathrm{l}$; Alltech, Carnforth, Lancs, UK) in dichloromethane $(80 \mu \mathrm{l})$. Fatty acid methyl esters were isolated via a water-hexane extraction. Samples were then evaporated to dryness in a centrifugal vacuum evaporator before dissolving in isooctane $(700 \mu \mathrm{l})$

\section{Gas chromatography-flame ionisation detector analysis}

A $6890 \mathrm{~N}$ gas chromatograph (Agilent, Winnersh Triangle, Berks, UK), fitted with an on-column injector, was used for $\mathrm{GC}$-flame ionisation detector analyses. Data acquisition was carried out using Chemstation Rev.B.01.03 software (Agilent) and data processing was carried out using Chromeleon 6.70 software (Dionex, Leeds, UK). An SP2340 column $(30 \mathrm{~m} \times 0.32 \mathrm{~mm}, 0.2 \mu \mathrm{m}$ film thickness; Supelco) plus a further $2 \mathrm{~m}$ of the same column as a sacrificial column and
$2 \mathrm{~m}$ deactivated silica retention gap (Alltech) were used for all analyses. Operating conditions were as follows: injection volume $0.5 \mu \mathrm{l}$; carrier gas $\mathrm{H}_{2}$ at a constant pressure of 7 pounds per square inch; oven program temperature $65^{\circ} \mathrm{C}$ held for $1 \mathrm{~min}$ then increased at $5^{\circ} \mathrm{C} / \mathrm{min}$ to $135^{\circ} \mathrm{C}$, then ramped at $2^{\circ} \mathrm{C} / \mathrm{min}$ to $200^{\circ} \mathrm{C}$ and finally at $10^{\circ} \mathrm{C} / \mathrm{min}$ to $250^{\circ} \mathrm{C}$, held for $5 \mathrm{~min}$ (total run time $57.5 \mathrm{~min}$ ); flame ionisation detector temperature $220^{\circ} \mathrm{C}$. Flame ionisation detector gas flows were: $\mathrm{H}_{2}, 30 \mathrm{ml} / \mathrm{min}$; air, $350 \mathrm{ml} / \mathrm{min}$; constant column plus makeup $\left(\mathrm{N}_{2}\right)$ flow, $25 \mathrm{ml} / \mathrm{min}$.

\section{Results}

Anthropometric and dietary characteristics of each diet group are shown in Table 1. Vegan women weighed, on average, $5 \mathrm{~kg}$ less than meat-eaters and vegetarians and had a correspondingly lower BMI. Smoking patterns were not significantly different between the diet groups (results not shown). Consumption of milk was significantly higher in the meat-eaters than the vegetarians, although intakes of other dairy foods including cheese, yoghurt and butter were similar between the two diet groups. Intakes of most nutrients differed significantly between the diet groups; meat-eaters had the highest intakes of energy,

Table 1. Lifestyle factors and dietary intakes in ninety-six women meat-eaters, vegetarians and vegans in EPIC-Oxford

(Arithmetic means and standard deviations)

\begin{tabular}{|c|c|c|c|c|c|c|c|}
\hline \multirow[b]{2}{*}{ Factor } & \multicolumn{2}{|c|}{$\begin{array}{l}\text { Meat-eaters } \\
\qquad(n 25)\end{array}$} & \multicolumn{2}{|c|}{$\begin{array}{l}\text { Lacto-ovo-vegetarians } \\
\qquad(n 25)\end{array}$} & \multicolumn{2}{|c|}{$\begin{array}{l}\text { Vegans } \\
(n 46)\end{array}$} & \multirow{2}{*}{$\begin{array}{c}\text { Test of } \\
\text { heterogeneity }(P)\end{array}$} \\
\hline & Mean & SD & Mean & SD & Mean & SD & \\
\hline \multicolumn{8}{|l|}{ Non-dietary variables } \\
\hline Age (years) & 42 & $12 \cdot 7$ & 46 & $14 \cdot 3$ & 44 & $12 \cdot 2$ & 0.57 \\
\hline Height (cm) & 163 & $5 \cdot 1$ & 162 & $6 \cdot 3$ & 162 & $9 \cdot 2$ & 0.59 \\
\hline Weight (kg) & $62 \cdot 3$ & $10 \cdot 4$ & $62 \cdot 5$ & $10 \cdot 5$ & $57 \cdot 1$ & $9 \cdot 8$ & 0.04 \\
\hline \multicolumn{8}{|l|}{ Food intakes (g/d) } \\
\hline Total meat ${ }^{*}$ & 88 & 55 & - & - & - & - & \\
\hline Ruminant meat $†$ & 30 & 28 & - & - & - & - & \\
\hline Fish $\ddagger$ & 48 & 33 & - & - & - & - & \\
\hline Oily fish & 18 & 21 & - & - & - & - & \\
\hline Milk & 336 & 162 & 250 & 138 & - & - & 0.05 \\
\hline Cheese & 17 & 17 & 16 & 12 & - & - & 0.69 \\
\hline Yoghurt & 39 & 46 & 45 & 44 & - & - & 0.67 \\
\hline \multicolumn{8}{|l|}{ Nutrient intakes (\% energy) } \\
\hline Energy (kJ) & 8740 & 2790 & 7420 & 1730 & 7460 & 2050 & 0.04 \\
\hline Total fat & $32 \cdot 1$ & $4 \cdot 2$ & 29.6 & 5.5 & $31 \cdot 8$ & $6 \cdot 3$ & 0.20 \\
\hline Fat from meat products* & $3 \cdot 6$ & 1.9 & - & - & - & - & \\
\hline Fat from ruminant meat products $\dagger$ & 1.0 & $1 \cdot 1$ & - & - & - & - & \\
\hline Fat from fish products $¥$ & $2 \cdot 2$ & $4 \cdot 8$ & - & - & - & - & \\
\hline Fat from dairy products§ & $12 \cdot 3$ & $4 \cdot 8$ & $12 \cdot 7$ & 5.9 & - & - & 0.77 \\
\hline SFA & $10 \cdot 4$ & $3 \cdot 1$ & 8.9 & $3 \cdot 1$ & $5 \cdot 8$ & $2 \cdot 2$ & $<0.0001$ \\
\hline MUFA & $10 \cdot 0$ & $1 \cdot 7$ & $8 \cdot 0$ & $2 \cdot 1$ & $8 \cdot 7$ & $2 \cdot 9$ & 0.01 \\
\hline PUFA & $5 \cdot 3$ & 1.4 & $5 \cdot 4$ & $1 \cdot 8$ & $7 \cdot 8$ & 2.7 & $<0.0001$ \\
\hline Protein & $17 \cdot 5$ & $2 \cdot 4$ & $13 \cdot 7$ & $2 \cdot 1$ & $13 \cdot 2$ & $2 \cdot 0$ & $<0.0001$ \\
\hline Carbohydrate & $48 \cdot 7$ & $3 \cdot 7$ & 54.5 & $5 \cdot 3$ & $52 \cdot 7$ & 5.5 & 0.0003 \\
\hline Alcohol & $1 \cdot 7$ & $1 \cdot 8$ & $2 \cdot 3$ & $4 \cdot 0$ & $2 \cdot 4$ & $3 \cdot 2$ & 0.69 \\
\hline \multicolumn{8}{|c|}{ Phospholipid fatty acid concentrations (mmol/l) } \\
\hline Pentadecanoic acid $(15: 0)$ & 0.22 & 0.05 & 0.23 & 0.06 & $0 \cdot 15$ & 0.05 & $<0.0001$ \\
\hline Heptadecanoic acid $(17: 0)$ & 0.49 & 0.12 & 0.47 & 0.06 & 0.37 & $0 \cdot 10$ & $<0.0001$ \\
\hline
\end{tabular}

* Total meat includes beef and beefburgers, lamb, poultry, pork, bacon, ham, Spam, sausages, meat pie and liver.

† Ruminant meat products include beef, beefburgers and lamb.

¥Fish products include white fish, oily fish, fried fish, fish cakes, shellfish and fish roe products.

$\S$ Dairy products include milk, cheese, cottage cheese, yoghurt, dairy desserts, cream and quiche. 
saturated fat, monounsaturated fat and protein (each as percentage energy), and the lowest intakes of PUFA and carbohydrate (each as percentage energy). With the exception of carbohydrate and monounsaturated fat intake, vegetarians had intermediate values for these nutrient intakes. Daily intakes of total fat and alcohol (percentage energy) were similar in the three diet groups. There were significant differences between the diet groups in the mean plasma concentrations of pentadecanoic acid and heptadecanoic acid (both $P_{\text {heterogeneity }}<0 \cdot 0001$ ), with meat-eaters having, on average, a $30-50 \%$ higher mean concentration than that of vegans.

Table 2 shows the associations between lifestyle factors and plasma phytanic acid concentration. There was no association between age, BMI or smoking and phytanic acid levels in these women. However, plasma phytanic acid concentration was significantly different between meat-eaters, vegetarians and vegans $\left(P_{\text {heterogeneity }}<0.0001\right)$; meat-eaters had a 6.7fold higher geometric mean plasma phytanic acid concentration than vegans $(5.77 v .0 .86 \mu \mathrm{mol} / 1 ; P<0.0001)$ and a $47 \%$ higher concentration than the vegetarians $(5.77 v$. $3.93 \mu \mathrm{mol} / \mathrm{l} ; P=0.016)$; the mean phytanic acid concentration was also significantly higher in vegetarians compared with vegans $(P<0.0001)$. After taking into account these differences by dietary group, plasma phytanic acid concentration was not associated with time of day of blood collection, time since last eaten at blood collection, days between blood collection and processing or assay batch (data not shown).

Pentadecanoic acid and heptadecanoic acid were strongly correlated with each other $(r 0.60)$ and with plasma phytanic acid concentrations ( $r 0.61$ and 0.55 for pentadecanoic acid and heptadecanoic acid, respectively). Table 3 shows the Spearman correlation coefficients between dietary intake of animal foods and fats and each of these fatty acids among meat-eaters and

Table 2. Association of age and lifestyle factors with phytanic acid concentration in ninety-six women meat-eaters, vegetarians and vegans

(Geometric means and $95 \%$ confidence intervals)

\begin{tabular}{|c|c|c|c|c|}
\hline \multirow[b]{2}{*}{ Factor } & \multirow{2}{*}{$\begin{array}{l}\text { Subjects } \\
\qquad(n)\end{array}$} & \multicolumn{2}{|c|}{$\begin{array}{c}\text { Phytanic acid } \\
\text { concentration }(\mu \mathrm{mol} / \mathrm{l})\end{array}$} & \multirow{2}{*}{$\begin{array}{c}\text { Test for } \\
\text { heterogeneity }(P)\end{array}$} \\
\hline & & $\begin{array}{l}\text { Geometric } \\
\text { mean }\end{array}$ & $95 \% \mathrm{Cl}$ & \\
\hline \multicolumn{5}{|l|}{ Age (years) } \\
\hline$<29$ & 17 & 1.78 & $1.05,3.03$ & \\
\hline $30-39$ & 17 & $2 \cdot 65$ & $1.56,4.50$ & \\
\hline $40-49$ & 20 & $2 \cdot 61$ & $1.60,4.50$ & \\
\hline $59-59$ & 29 & $1 \cdot 79$ & $1 \cdot 19,2 \cdot 69$ & \\
\hline $60+$ & 13 & 1.94 & $1.06,3.55$ & 0.64 \\
\hline \multicolumn{5}{|l|}{ BMI $\left(\mathrm{kg} / \mathrm{m}^{2}\right)^{*}$} \\
\hline$<20.1$ & 24 & $2 \cdot 32$ & $1 \cdot 73,3 \cdot 10$ & \\
\hline $20 \cdot 1-21 \cdot 7$ & 24 & $2 \cdot 01$ & $1.51,2.67$ & \\
\hline $21 \cdot 8-24 \cdot 1$ & 24 & 1.95 & $1.46,2.59$ & \\
\hline $24 \cdot 2+$ & 24 & $2 \cdot 13$ & $1 \cdot 60,2 \cdot 83$ & 0.81 \\
\hline \multicolumn{5}{|l|}{ Smoking } \\
\hline Never & 60 & 2.50 & $1.89,3.30$ & \\
\hline Former & 27 & 1.51 & $1 \cdot 00,2 \cdot 28$ & \\
\hline Current & 9 & 1.72 & $0.87,3.52$ & 0.13 \\
\hline \multicolumn{5}{|l|}{ Diet group } \\
\hline Meat-eater & 25 & $5 \cdot 77$ & $4.40,7.57$ & \\
\hline Vegetarian & 25 & 3.93 & $3 \cdot 00,5 \cdot 15$ & \\
\hline Vegan & 46 & 0.86 & $0.70,1.05$ & $<0.0001$ \\
\hline
\end{tabular}

${ }^{*}$ Additionally adjusted for diet group. vegetarians, where appropriate. Overall, the strongest dietary correlate of plasma phytanic acid was intake of dairy fat $(r 0.68 ; P<0.0001)$. Ruminant meat or fat from ruminant meat was not significantly associated with phytanic acid concentration ( $r 0.21$ and $0 \cdot 20$, respectively). Pentadecanoic acid and heptadecanoic acid were both positively correlated with butter intake. Pentadecanoic acid was correlated with fat from dairy products $(r 0.48)$, but heptadecanoic acid was not $(r 0.06)$.

\section{Discussion}

The findings from the present study show that plasma phytanic acid concentrations are higher in meat-eaters than in vegetarians, and that concentrations in both groups are substantially higher than in vegans. The very low circulating phytanic acid concentration in vegans, who consume no animal products, provides direct evidence that, at least in the $\mathrm{UK}$, phytanic acid is derived almost solely from the dietary intake of animal products. The strongest dietary determinant appeared to be the intake of dairy fat.

The main strength of the present study is the large variation in diet between the dietary groups. Weaknesses are that the FFQ may not provide very accurate estimates of the intake of fat, and that the sample size was only moderate. Furthermore, in the analyses of plasma fatty acids in relation to consumption of certain foods, the number of subjects for examining meat and fish is small because the vegetarians and vegans are excluded from this analysis. Thus the conclusions concerning the relative importance of ruminant meat, fish and dairy products as sources of phytanic acid are tentative.

The circulating concentration of phytanic acid among meat-eaters in the present study is comparable with that in other studies conducted in Western populations ${ }^{21,23}$. However, very few studies have examined the association between dietary intake and phytanic acid concentrations and, as far as we are aware, the present study is the first to assess phytanic acid concentrations in non-meat-eaters. Our finding that phytanic acid levels are more strongly correlated with the intake of fat from dairy products than with the intake of meat or ruminant meat products is consistent with one previous study that found a correlation of 0.16 for meat and 0.24 for dairy intake ${ }^{21}$ and perhaps reflects the higher proportion of fat intake derived from dairy products than from ruminant meat products. Indeed, among meateaters, only $4 \%$ of total fat intake was derived from meat products, $76 \%$ of whom stated they ate as little as possible of the visible fat on meat. This is substantially lower than the national average of $20 \%$ of fat intake derived from meat products for UK women estimated in the National Diet and Nutrition Survey ${ }^{24}$ and most probably reflects the health-conscious behaviour of our participants.

The present results suggest that total phytanic acid concentration in plasma samples can be reliably measured in largescale epidemiological studies using the GLC-MS techniques; the assay procedure used in the present study had a low intraand inter-batch variation, exhibited $4 \mathrm{~h}$ stability at room temperature and was robust to several freeze-thaw cycles. Further, lifestyle and demographic factors including age, anthropometry and smoking were not strongly associated with circulating phytanic acid concentrations, and phytanic 
Table 3. Associations between food and nutrient intake and plasma concentrations of phytanic acid, pentadecanoic acid and heptadecanoic acid

(Spearman correlations)

\begin{tabular}{|c|c|c|c|}
\hline Food or nutrient & Phytanic acid & Pentadecanoic acid & Heptadecanoic acid \\
\hline Total dairy and ruminant meat $†$ & 0.34 & $0.50^{* *}$ & 0.35 \\
\hline Total meat† & $0 \cdot 12$ & 0.23 & 0.06 \\
\hline Ruminant meat (beef and lamb) $†$ & 0.21 & $0.42^{*}$ & $0 \cdot 10$ \\
\hline Total fish† & -0.25 & -0.30 & 0.37 \\
\hline Milk & 0.31 & 0.17 & $0 \cdot 16$ \\
\hline Cheese & $0.44^{\star \star *}$ & 0.22 & 0.07 \\
\hline Yoghurtł & $-0 \cdot 10$ & 0.01 & -0.08 \\
\hline Butter $\ddagger$ & 0.22 & $0.47^{\star \star \star}$ & $0.40^{\star *}$ \\
\hline Fat from total meat products (\% energy) $\dagger$ & 0.07 & 0.08 & -0.01 \\
\hline Fat from ruminant meats ( $\%$ energy) $\dagger$ & 0.20 & 0.37 & 0.14 \\
\hline Fat from fish products (\% energy)† & -0.19 & $-0 \cdot 21$ & 0.33 \\
\hline Fat from dairy products (\% energy) $\ddagger \S$ & $0.68^{\star * * *}$ & $0.48^{\star \star \star}$ & 0.06 \\
\hline Fat from dairy products and ruminant meat (\% energy) $\uparrow \S$ & $0 \cdot 65^{\star \star \star}$ & $0 \cdot 61^{\star * \star}$ & 0.16 \\
\hline
\end{tabular}

${ }^{\star} P<0.05,{ }^{\star \star} P<0.01,{ }^{\star \star \star} P<0.001,{ }^{\star \star * \star} P<0.0001$.

$\dagger$ Meat-eaters only ( $n$ 25)

$\ddagger$ Meat-eaters and vegetarians only $(n 50)$.

$\S$ Dairy products include milk, cheese, cottage cheese, yoghurt, dairy desserts, cream and quiche.

acid concentrations appeared to be influenced largely by dietary intake of dairy products.

The high correlation observed between dairy fat intake and phytanic acid concentration in this population $(r 0.68)$ is perhaps surprising given the well-known inaccuracies of measuring food and nutrient intake from FFQ. However, a previous validation study found that nutrient intakes estimated from the FFQ were strongly correlated with estimates from $16 \mathrm{~d}$ weighed records, with correlations of 0.52 and 0.55 for energy and fat intake, respectively ${ }^{25}$. Further, the correlations observed between dairy fat intake and the concentrations of heptadecanoic and pentadecanoic acid are consistent with other studies that have measured these fatty acids in serum phospholipids and adipose tissue ${ }^{26-29}$, suggesting that the FFQ has similar validity to those used by other researchers in assessing dietary fat intake.

Like phytanic acid, pentadecanoic acid and heptadecanoic acid are synthesised by bacterial flora in the rumen of ruminants ${ }^{30}$ and, because they are not produced endogenously, have been proposed as suitable biological markers of dairy and other ruminant fat intake $\mathrm{e}^{26-28}$. However, in the present study, phytanic acid concentration was more strongly associated with dairy fat intake and exhibited much larger differences between dietary groups than either pentadecanoic acid or heptadecanoic acid; indeed, phytanic acid concentrations were nearly seven times higher in meat-eaters than vegans, compared with more modest differences of approximately $50 \%$ for pentadecanoic acid and heptadecanoic acid. These results therefore suggest that phytanic acid is a suitable alternative biological marker of dairy fat intake.

There is circumstantial evidence that phytanic acid and the enzyme required for its metabolism, AMACR, may be related to cancer development. In vitro studies have shown phytanic acid, and its $\alpha$-oxidation product, pristanic acid, to directly increase AMACR protein expression ${ }^{5,6}$ and clinical studies have shown up to a 9-fold increase in AMACR protein expression in cancers of the prostate, breast and colon and their precursor lesions, compared with normal tissue ${ }^{7-14}$, with a concomitant increase in enzyme activity ${ }^{31,32}$. Further circumstantial evidence for a role of phytanic acid in the development of prostate cancer comes from a study that has found sequence variants of the AMACR gene to be associated with hereditary prostate cancer risk ${ }^{33}$ and a small US case-control study that found circulating phytanic acid concentrations to be higher in men with prostate cancer than in controls ${ }^{21}$. Further work is needed to examine the association between phytanic acid concentrations and AMACR expression in vivo, and to determine whether circulating phytanic acid concentrations are predictive of cancer risk in the general population.

In conclusion, the results from the present study show that plasma phytanic acid concentrations can be reliably measured in large-scale epidemiological studies and that circulating phytanic acid level is strongly associated with dietary intake of fat from dairy products. Phytanic acid is of potential importance because of the hypothesis that a high intake of dietary phytanic acid may be related to up regulation of the enzyme AMACR in cancer development.

\section{Acknowledgements}

The EPIC-Oxford study is supported by Cancer Research UK and The Medical Research Council. We thank the participants in EPIC-Oxford.

\section{References}

1. Armstrong B \& Doll R (1975) Environmental factors and cancer incidence and mortality in different countries, with special reference to dietary practices. Int J Cancer 15, 617-631.

2. Allen NE, Appleby PN, Davey GK \& Key TJ (2000) Hormones and diet: low insulin-like growth factor-I but normal bioavailable androgens in vegan men. Br J Cancer 83, 95-97.

3. Gunnell D, Oliver SE, Peters TJ, et al. (2003) Are diet-prostate cancer associations mediated by the IGF axis? A cross-sectional analysis of diet, IGF-I and IGFBP-3 in healthy middle-aged men. Br J Cancer 88, 1682-1686.

4. Thornburg T, Turner AR, Chen YQ, Vitolins M, Chang B \& Xu J (2006) Phytanic acid, AMACR and prostate cancer risk. Future Oncol 2, 213-223. 
5. Wierzbicki AS, Lloyd MD, Schofield CJ, Feher MD \& Gibberd FB (2002) Refsum's disease: a peroxisomal disorder affecting phytanic acid $\alpha$-oxidation. J Neurochem 80, 727-735.

6. Mobley JA, Leav I, Zielie P, Wotkowitz C, Evans J, Lam YW, L'Esperance BS, Jiang Z \& Ho SM (2003) Branched fatty acids in dairy and beef products markedly enhance $\alpha$-methylacyl-CoA racemase expression in prostate cancer cells in vitro. Cancer Epidemiol Biomarkers Prev 12, 775-783.

7. Xu J, Stolk JA, Zhang X, Silva SJ, Houghton RL, Matsumura M, Vedvick TS, Leslie KB, Badaro R \& Reed SG (2000) Identification of differentially expressed genes in human prostate cancer using subtraction and microarray. Cancer Res 60, $1677-1682$

8. Jiang Z, Fanger GR, Woda BA, Banner BF, Algate P, Dresser K, Xu J \& Chu PG (2003) Expression of $\alpha$-methylacyl-CoA racemase (P504s) in various malignant neoplasms and normal tissues: a study of 761 cases. Hum Pathol 34, $792-796$.

9. Jiang Z, Wu CL, Woda BA, et al. (2004) $\alpha$-Methylacyl-CoA racemase: a multi-institutional study of a new prostate cancer marker. Histopathology 45, 218-225.

10. Luo J, Zha S, Gage WR, et al. (2002) $\alpha$-Methylacyl-CoA racemase: a new molecular marker for prostate cancer. Cancer Res 62, 2220-2226.

11. Nassar A, Amin MB, Sexton DG \& Cohen C (2005) Utility of $\alpha$-methylacyl coenzyme A racemase (p504s antibody) as a diagnostic immunohistochemical marker for cancer. Appl Immunohistochem Mol Morphol 13, 252-255.

12. Rubin MA, Zhou M, Dhanasekaran SM, Varambally S, Barrette TR, Sanda MG, Pienta KJ, Ghosh D \& Chinnaiyan AM (2002) $\alpha$-Methylacyl coenzyme A racemase as a tissue biomarker for prostate cancer. JAMA 287, 1662-1670.

13. Witkiewicz AK, Varambally S, Shen R, Mehra R, Sabel MS, Ghosh D, Chinnaiyan AM, Rubin MA \& Kleer CG (2005) $\alpha$-methylacyl-CoA racemase protein expression is associated with the degree of differentiation in breast cancer using quantitative image analysis. Cancer Epidemiol Biomarkers Prev 14, $1418-1423$

14. Zhou M, Chinnaiyan AM, Kleer CG, Lucas PC \& Rubin MA (2002) $\alpha$-Methylacyl-CoA racemase: a novel tumor marker over-expressed in several human cancers and their precursor lesions. Am J Surg Pathol 26, 926-931.

15. Body DR (1977) Characterization of bovine rumen liquor isoprenoid hydrocarbons with reference to dietary phytol. Lipids 12, 204-207.

16. van den Brink DM \& Wanders RJ (2006) Phytanic acid: production from phytol, its breakdown and role in human disease. Cell Mol Life Sci 63, 1752-1765.

17. Riboli E \& Kaaks R (1997) The EPIC Project: rationale and study design. European Prospective Investigation into Cancer and Nutrition. Int J Epidemiol 26, Suppl. 1, S6-S14.

18. Davey GK, Spencer E, Appleby PN, Allen N, Knox K \& Key TJ (2003) EPIC-Oxford: baseline characteristics and nutrient intakes in a cohort of 33,883 meat-eaters and 31,546 non meat-eaters in the UK. Public Health Nutr 6, 259-269.
19. Holland B, Welch AA, Unwin ID, Buss DH, Paul AA \& Southgate DAT (1991) McCance and Widdowson's The Composition of Foods, 5th ed. Cambridge, UK: Royal Society of Chemistry and Ministry of Agriculture, Fisheries and Food.

20. Ministry of Agriculture Fisheries and Food (1993) Food Portion Sizes, 2nd ed. London: H.M. Stationery Office.

21. Xu J, Thornburg T, Turner AR, et al. (2005) Serum levels of phytanic acid are associated with prostate cancer risk. Prostate 63, 209-214.

22. Vreken P, van Lint AE, Bootsma AH, Overmars H, Wanders RJ \& van Gennip AH (1998) Rapid stable isotope dilution analysis of very-long-chain fatty acids, pristanic acid and phytanic acid using gas chromatography-electron impact mass spectrometry. J Chromatogr B Biomed Sci Appl 713, 281-287.

23. ten Brink HJ, Stellaard F, van den Heuvel CM, Kok RM, Schor DS, Wanders RJ \& Jakobs C (1992) Pristanic acid and phytanic acid in plasma from patients with peroxisomal disorders: stable isotope dilution analysis with electron capture negative ion mass fragmentography. J Lipid Res 33, 41-47.

24. Office for National Statistics (2003) The National Diet and Nutrition Survey: Adults Aged 19 to 64 Years. Volume 2: Energy, Protein, Carbohydrate, Fat and Alcohol Intake. London: H.M. Stationery Office. http://www.food.gov.uk/ multimedia/pdfs/ndnsv2.pdf

25. Bingham SA, Gill C, Welch A, et al. (1997) Validation of dietary assessment methods in the UK arm of EPIC using weighed records, and 24-hour urinary nitrogen and potassium and serum vitamin $\mathrm{C}$ and carotenoids as biomarkers. Int J Epidemiol 26, Suppl. 1, S137-S151.

26. Smedman AE, Gustafsson IB, Berglund LG \& Vessby BO (1999) Pentadecanoic acid in serum as a marker for intake of milk fat: relations between intake of milk fat and metabolic risk factors. Am J Clin Nutr 69, 22-29.

27. Wolk A, Vessby B, Ljung H \& Barrefors P (1998) Evaluation of a biological marker of dairy fat intake. Am J Clin Nutr 68, 291-295.

28. Wolk A, Furuheim M \& Vessby B (2001) Fatty acid composition of adipose tissue and serum lipids are valid biological markers of dairy fat intake in men. J Nutr 131, 828-833.

29. Brevik A, Veierod MB, Drevon CA \& Andersen LF (2005) Evaluation of the odd fatty acids 15:0 and 17:0 in serum and adipose tissue as markers of intake of milk and dairy fat. Eur J Clin Nutr 59, 1417-1422.

30. Wu Z \& Palmquist DL (1991) Synthesis and biohydrogenation of fatty acids by ruminal microorganisms in vitro. $J$ Dairy $S c i$ 74, 3035-3046.

31. Kumar-Sinha C, Shah RB, Laxman B, et al. (2004) Elevated $\alpha$-methylacyl-CoA racemase enzymatic activity in prostate cancer. Am J Pathol 164, 787-793.

32. Zha S, Ferdinandusse S, Denis S, Wanders RJ, Ewing CM, Luo J, De Marzo AM \& Isaacs WB (2003) $\alpha$-Methylacyl-CoA racemase as an androgen-independent growth modifier in prostate cancer. Cancer Res 63, 7365-7376.

33. Zheng SL, Chang BL, Faith DA, et al. (2002) Sequence variants of $\alpha$-methylacyl-CoA racemase are associated with prostate cancer risk. Cancer Res 62, 6485-6488. 